\title{
Changó, el Gran Putas: Formas DE RESISTENCIA E IDENTIDAD ESCLAVIZADA EN LOS ESTUDIOS POSCOLONIALES*
}

Fecha de recepción: 12 de octubre de 2013 Fecha de aprobación: 29 de octubre de 2013

\section{Resumen}

Este ensayo va a centrarse en el análisis de las formas de resistencia e identidad esclavizada presentes en Changó, el gran putas de Manuel Zapata Olivella, a través del análisis de los discursos hegemónicos y subalternos que hacían parte del sistema de poder, y la intervención de las teorías o estudios poscoloniales que cuestionan dichas perspectivas para redefinir las diferencias de las identidades contradictorias y desarrollar de esta manera literaturas deslindadas de las estructuras ideológicas y hegemónicas.

Palabras Clave: resistencia, discurso, identidad, subalterno, estudios poscoloniales.

* Artículo de reflexión desarrollado en la investigación que está en proceso de revisión titulada "Africanía, memoria y resistencia en Changó, el gran putas" de la Maestría en Literatura Hispanoamericana y del Caribe de la Universidad del Atlántico

Citar: Montenegro De la Hoz, N. (Enero - Junio de 2014). Changó, el Gran Putas: Formas de Resistencia e Identidad Esclavizada en los Estudios Poscoloniales. La Palabra (24), 59 - 66
Nellys Montenegro De la $\mathrm{Hoz}$ Universidad del Atlántico Universidad Popular del Cesar, Colombia montenegronellys@hotmail.com

Licenciada en Lengua Castellana e Inglés de la Universidad Popular del Cesar y candidata a Magíster en Literatura Hispanoamericana y del Caribe de la Universidad del Atlántico. 

IDENTITY IN Postcolonial STUdies

\begin{abstract}
This essay studies the forms of resistance and enslaved identity present in Changó el gran putas [Chango, the biggest badass], by Manuel Zapata Olivella, through the analysis of the hegemonic and subaltern discourse that formed part of the system of power, and the intervention of postcolonial theories or studies, which question these perspectives, to redefine the differences between contradictory identities, in this way developing literatures that stand apart from ideological and hegemonic structures.
\end{abstract}

Key words: resistance, discourse, identity, subaltern, postcolonial studies.

\title{
Chango, el Gran Putas: Des Formes de Resis- TANCE ET D'identitè Esclavagee Dans LeS Etudes Postcoloniaux
}

\section{Résumé}

Cet article de réflexion va se centrer dans l'analyse des formes de résistance et d'identité esclavagée présentes dans Changó, el gran Putas de Manuel Zapata Olivella, à travers l'analyse des discours hégémoniques et subalternes qui faisaient partie du système de pouvoir, et l'intervention des théories o des études postcoloniaux qui remettent en question ces perspectives-là pour redéfinir les différences des identités contradictoires. Cela, pour développer de cette manière des littératures délimitées des structures idéologiques été hégémoniques.

Mots clés: Résistance, discours, identité, subalterne, études postcoloniaux. 
La impugnación del mundo colonial por el colonizado no es una confrontación racional de los puntos de vista. No es un discurso sobre lo universal, sino la afirmación desenfrenada de una originalidad formulada como absoluta. El mundo colonial es un maniqueo. No le basta al colono limitar físicamente, es decir, con ayuda de sus policías y sus gendarmes, el espacio del colonizado. Como para ilustrar el carácter totalitario de la explotación colonial, el colono hace del colonizado una especie de quinta esencia del mal (Franz, 2001, p. 35).

Con esta cita queda claro que al colono no le basta con limitar físicamente al colonizado sino que debe hacer de este "la quinta esencia del mal". Es así como el colonialismo establece el universo del colonizado al indicarle las conductas sociales que debe seguir, y con ello reduce la sociedad del colonizado a una sociedad vulnerable, desarraigada y desprovista de valores, situación que lleva al colonizado a un mutismo absoluto. Es importante destacar la idea de una sociedad generada por la colonización, que persigue culturas desiguales en nombre de una ideología civilizadora, en la cual el hombre visualiza al otro como ser inferior y por ende, pierde valores intrínsecos que de una forma u otra le impulsan a destruirse a sí mismo.

Es entonces cuando los colonizadores conciben los territorios colonizados como lugares propicios para sacar a flote su lado más oscuro, que al final va en deterioro de las sociedades colonizadas; de ahí, que los primeros intentos de los colonizadores por lograr de una manera eficaz el control de un grupo fueran a través de la imposición de un discurso de poder ante la mentalidad subalterna, logrando que el dominado adoptara un criterio similar a su dominador, es decir, conseguir que el dominado sustituya sus características culturales por las del dominador. De este modo, la sociedad colonial se constituyó bajo un principio de desigualdad, debido a que su objetivo principal era establecer mecanismos que le llevaran a un control eficaz sobre los colonizados, sin embargo, las características culturales del colonizado no desaparecieron completamente, persistieron en el interior del grupo colonizado oponiéndose de esta forma al sistema colonial.

A partir de ahí, las teorías o estudios poscoloniales aportan nuevas perspectivas y al mismo tiempo cuestionan las nociones hegemónicas, situación que lleva a proponer reescrituras desde el hecho de querer redefinir las diferencias de las identidades contradictorias en los espacios dominados anteriormente por el discurso hegemónico colonialista, debido a que el poder y el discurso pertenecían enteramente a él, es decir, desarrollar litera- turas deslindadas de las estructuras ideológicas y hegemónicas extranjeras; no obstante, ningún proceso que implique identidad se constituye por sí mismo; todo lo contrario, este requiere de experiencias compartidas, esto es,

(...) el desarrollo y el mantenimiento de cualquier cultura requieren la existencia de otro alter ego diferente y competitivo. La creación de una identidad (...), implica establecer antagonistas y «otros» cuya realidad esté siempre sujeta a una interpretación y a una reinterpretación permanentes con «nosotros»". Lejos de ser algo estático, la identidad de uno mismo o la del «otro» es un muy elaborado proceso histórico, social, intelectual y político que tiene lugar en un certamen, en el cual intervienen personas e instituciones de todas las sociedades (Said, 2002, p. 436).

Cuando el colonizador se da cuenta de que la construcción de su discurso no solo le pertenece a él y que requiere de la existencia de una contraparte subalterna e inferior que resiste y reelabora las representaciones impuestas, se considera que

Tras el periodo de resistencia primaria, en el que literalmente se lucha contra la intrusión extranjera, viene el periodo segundo, es decir, la resistencia cultural, durante la cual se realizan esfuerzos para reconstituir esa comunidad pulverizada 
y salvar o restaurar el sentimiento y el hecho mismo de la comunidad contra las presiones del sistema colonial (Said, 1996, p. 327).

Son estos procesos de resistencia cultural los que le dan una voz al subalterno para que pueda constituir su presencia en los discursos dominantes y a su vez pueda luchar desde allí con y desde sus potencialidades. Fue entonces cuando se dieron los primeros asomos de rebelión; la idea de la abolición de la esclavitud en el siglo XIX en los territorios del Caribe empezó a formarse, sin embargo este fue un proceso lento y desigual, comenzó en Haití en 1804 y terminó en Brasil en 1888. Los esclavizados acogieron distintas formas de resistencia al dominio de los amos: la lucha, la huida, las sublevaciones o rebeliones. En el caso de Haití la abolición se abrió camino en 1791 con la orientación de Boukman: 'Y los esclavos alzados, después de matar a todos los amos se proclamaran dueños de la tierra.” (Zapata, 1983, p. 173).

En el caso de Colombia, la conformación de palenques se constituyó en una forma de resistencia. Estos espacios sociales étnicos africanos se organizaron en el proceso de la esclavización, cuando los esclavizados escapaban de sus amos refugiándose en lugares remotos de la selva en busca de la libertad, en ese instante dejaban de ser esclavizados y se convertían en cimarrones:
En el plano cultural, la cimarronearía se manifestó de una forma igualmente saludable: al buscar la nueva verdad de sus vidas, los esclavos de América tomaron de la angustia misma de la condición negra su profundo dinamismo para mantener y hacer prosperar en ellos el sentido universal de libertad y de la identidad humana (Depreste, 1996, p. 95).

En estos espacios creaban sociedades en las cuales los cimarrones podían revivir sus propios estilos de vida concernientes a su cultura afro opuesta a la sociedad colonial, esto es, centros de actividad de resistencia; ejemplo de ello es el Palenque de San Basilio en el departamento de Bolívar que aún mantiene las manifestaciones culturales africanas y su lenguaje nativo. En este tipo de espacios sociales el discurso oculto ya no era necesario, porque estaban lejos del alcance o control de los dominadores, además; este espacio era compartido por personas cercanas que compartían una misma experiencia de dominación, de esta manera: "Dispusimos que fundaríamos nuestro reino en la ciudad de los amos: un patio común para las naciones fula, mina, la angola y conga. Nos reuníamos a tocar y bailar tambor" (Zapata, 1983, p. 132).

Para la constitución de dichos espacios, la intervención de Benkos Biojó fue el detonante liberador del pueblo africano al incitar a los otros esclavizados a escapar de la mano esclavista y conformar un palenque. Este joven valiente, luchador y defensor orgulloso de su cultura no estaba de acuerdo con la esclavitud y sostenía: "Oíd, oídos del Muntu. ¡Oíd! Aquí nace el vengador, ya está con nosotros el brazo del fuego, la muñeca que se escapará de los grillos, el diente que destrozará las cadenas" (Zapata, 1983, p. 97). De este modo, Biojó afianzó el cimarronaje como una herramienta contra el poder ejercido hasta entonces por los dominadores. Benkos Biojó, como protegido de Elegba, fue escogido por Changó para ser líder y luchar contra la infamia, reivindicar al esclavizado, construir una nueva sociedad; la sociedad palenquera.

Por otra parte, Benkos Biojó es pieza importante en el vínculo del proceso de desculturación ejercido principalmente por el discurso religioso impartido por el Tribunal de la Santa Inquisición, con el objetivo de unificar la cultura afro e indígena a la cultura blanca al eliminar los aspectos culturales de la etnia afro, en la medida en que Benkos se convierte en ese contacto unificador desde su nacimiento con la guía del padre Claver, quien se muestra en la obra como un ser perturbado y desolado cuyo trabajo de salvación de los esclavizados se convierte más en una búsqueda desesperada por salvar almas para su Dios 
que en una ayuda desinteresada directa para los esclavizados; esto es claro cuando en la conmemoración del ritual de nacimiento del rey Benkos los esclavizados con ayuda de tambores y danzas pretenden exaltarlo, pero el padre Claver al observar les azota, los rocía con agua bendita y les dice: “¡Malditos herejes! ¿Sois vosotros los mismos a quienes yo he bautizado?" (p. 100), con ello se demuestra una vez más la incapacidad del opresor de salir de su lógica binaria y sus connotaciones erróneas.

De esta manera, se dan dos casos ambivalentes en cuanto a la asimilación de valores impuesta por el colonizador. Tal es el caso del debate entre el padre Claver y Benkos Biojó, sobre las virtudes del cristiano, impuestas por el colonizador europeo y el espíritu rebelde del subalterno africano, quien trata de subvertir la retórica colonizadora cristiana debido a que la considera como una traición a su vínculo cultural ancestral, dado que el discurso colonizador le dice: "—Tienes que ser manso y sumiso a tu Dios. En las contrariedades ¿por qué no hacer lo que hace el asno? Si lo ultrajan, calla. Si se le olvida, se resigna a ser el último. Si se le maltrata, sufre sin quejarse. Si se le niega alimento, rumia su hambre (...) En suma, (...) ¡Buen ejemplo para el verdadero siervo de Dios!" (Zapata, 1983, p. 139), a lo que el discurso subalterno responde: "-Sepa padre
(...) que poca diferencia hace usted en las obras del Señor. Al burro le hizo torpe y bien hace callar, pero a los hombres nos dio entendimiento. $\mathrm{Si}$ yo fuera un asno no aspirara a tener una corona aunque fuera de papel" (p. 139). Por lo tanto el personaje de Benkos representa una resistencia al poderío colonizador.

Asimismo, Benkos representa al joven devoto a quien le era permitido ser sacristán en los bautizos, testigo en los matrimonios y acompañante del padre Claver en sus predicaciones. Sin embargo, este niño es el elegido para enfrentar a los colonizadores y restaurar la identidad de su etnia, por lo que, secretamente, recibe las revelaciones del Babalao, donde se le anuncia que el Muntu, que debe mezclar su sangre con el blanco y el indígena porque de esta forma el Muntu dilapidaría su sangre y el blanco mancillaría la suya dado que el esclavizado pasaría a ser "esclavizado de Dios" y por ello le liberaría de ser "esclavizado del blanco", de ahí que:

\footnotetext{
Otro se niega a recibir el bautizo, alegando que no podía volver a nacer en la otra vida porque su kulonda ha sido fecundado por su ancestro solo una vez (...) Anselmo Mina, después de recibir el agua bautismal se huyó dejando dicho que si era esclavo de Cristo no podía tener dos amos (Zapata, 1983 , p. 130).
}

La resistencia espiritual iniciada con Benkos aumentaría con el crecimiento del ejército de libertos, es decir, lo que inició de manera indisoluble en el discurso religioso llega a demostrarle a Loba Blanca que no eran los dueños de una aculturación total; a pesar de haber marcado su piel sus únicos dueños eran sus Orichas. De esta forma, Benkos, Mackandal, Bouckman, Malcom X y Martín Luther King como parte del Muntu quisieron de alguna forma superponer su cosmogonía mediante un proceso transculturador que lograra establecer su cultura a partir de la oralidad, no obstante, esta fue vista como escéptica, motivo por el cual se trató de invisibilizarla, pero el afro constituyó una cultura emergida en la hibridación de sus tradiciones desarticuladas, lo que trajo consigo la transculturación, tal como lo señala Fernando Ortiz:

Todo cambio de cultura, o como diremos desde ahora en adelante, toda transculturación, es un proceso en el cual siempre se da algo a cambio de lo que se recibe; es un "toma y daca", como dicen los castellanos. Es un proceso en el cual ambas partes de la ecuación resultan modificadas. Un proceso del cual emerge una nueva realidad, compuesta y compleja; una realidad que no es una aglomeración mecánica de caracteres, ni siquiera un mosaico, sino un fenómeno nuevo, original e independiente. 
Para describir tal proceso el vocablo de latinas raíces transculturación proporciona un término que no contiene la implicación de una cierta cultura hacia la cual tiene que tender la otra, sino una transición entre dos culturas, ambas activas, ambas contribuyentes con sendos aportes, y ambas cooperantes al advenimiento de una nueva realidad de civilización. (1978, pp. 4-5).

Todo esto llevó a una transdiscursividad nacida en la hibridación del nuevo ser afroamericano, ligada a su nueva realidad poscolonial, que trajo consigo un nuevo lenguaje, nuevas formas de expresión en la música y la danza, a través de las cuales los afro descendientes nunca dejarán atrás sus raíces ancestrales, sino que constituirán un transdiscurso sustentado en su cultura y la cultura que establece el dominio. Es así como Zapata Olivella refleja el pensamiento mítico, oral y emancipatorio de la cultura afroamericana, desde la unión de acontecimientos de referencia histórica y mítica, los cuales ayudan a la construcción del ser afroamericano a partir de su código oral y sistema narrativo escritural de la cultura letrada dominante. Zapata Olivella personaliza al hombre dueño de un discurso de resistencia, conocedor de la fuerza y plenitud de la palabra, de ahí que los esclavizados que llegaron desde África y sus descendientes trataron por todas las formas posibles, de mantener sus ritos a pesar de la represión.
El cuerpo y las serpientes de Elegba: templos de resistencia

David Le Breton sostiene que: "Cada sociedad esboza, en el interior de su visión de mundo, un saber singular sobre el cuerpo: sus constituyentes, sus usos, sus correspondencias. Le otorga sentido y valor" (1995, p. 8). A partir de este pensamiento, es posible analizar una sociedad a través del cuerpo, puesto que en él se establecen distintas estructuras sociales, religiosas, entre otras, que integran al hombre con sus dioses.

Por lo tanto, esta integración llevó a plantear en el período colonial una amplia diferencia respecto a la concepción del cuerpo entre esclavizados y colonizadores. Para los esclavizados, el cuerpo va ligado a aspectos de su religiosidad. En cuanto a los colonizadores, el cuerpo es sinónimo de pecado $\mathrm{y}$, por lo tanto, es merecedor de restricciones: "Nuevos grilletes se prendieron a nuestros brazos y una larga cadena une todas las argollas. Así avanzan en sus mañas para encadenar y manejarnos" (Zapata, 1983, p. 37).

Para el esclavizado su cuerpo es pasión y turbación, es el medio a través del cual percibe el mundo, y una manera para llevarlo a cabo es a partir de las expresiones propias de su cuerpo, las cuales generan un lenguaje: el baile, este permite que el hombre y la mujer se liberen espiritualmente: "sobreponiéndose al látigo, marchamos en traílla palmoteando en coro y bailando cantos de nuestros padres africanos" (Zapata, 1983, p. 140).

En cuanto al aspecto religioso del cuerpo, los esclavizados, basándose en que “el ser humano es un verdadero altar vivo en el que pueden ser invocadas la presencia de las entidades sobrenaturales" (Dos Santos, 1977, p. 122), podían sentir la religión de un modo más vivo, al percatarse que su cuerpo se constituía como un espacio para la supervivencia emocional y espiritual.

En relación a las serpientes de Elegba, los ancestros u Orichas se convierten en la vOz y memoria de los ekobios luego de su travesía. Entre el grupo de los ekobios, esclavizados y libertos, solo algunos son los elegidos para portar el símbolo que representa la memoria africana en tierras lejanas. Ese símbolo lo representa una serpiente mordiéndose la cola: "las serpientes de Tamin / las serpientes mágicas / vida y muerte inmortales / símbolos del Muntu / en el exilio" (Zapata, 1983, p. 23). Símbolo de vida y muerte en la continuidad del tiempo y del eterno retorno, escogida entre muchos otros porque es un animal dotado de grandes ventajas como agilidad, resistencia 
y fuerza, habilidades útiles para el Muntu, las cuales ayudarán a identificar su presencia en el exilio:

\begin{abstract}
Serpiente burladora de trampas / movimientos rápidos de ardilla. / Su pecho coraza de rinoceronte / potente su mandíbula, garra de león. / El vaho, los sudores, la saliva / aceitan su resbalosa piel de anguila / para limar, para roer los cepos / en la dentada quijada de la Loba / que en la guarida de las bodegas / tritura la luz, la vida y los huesos (...). Dos serpientes mordiéndose las colas / identificarán su presencia / en la tiránica tierra del exilio. / Por voluntad de Elegba / será su símbolo y mensajero / capitán de las revueltas tribus / su combatiente compañero. (1983, p. 41).
\end{abstract}

El símbolo de la serpiente mordiéndose la cola está acompañado por el llamado que un ancestro le hace a uno de los elegidos. Uno de estos elegidos es Arún, un ekobio que se ve sorprendido por el dibujo de las culebras de Elegba que un anciano kru hace en la arena: "Fue entonces cuando descubrió la cicatriz en sus pómulos, borrada por los soles y los años" (Zapata, 1983, p. 44). Entonces el anciano que días antes no había pronunciado palabra alguna, le dice: "-El elegido de Elegba necesita tu ayuda" (p. 44).

Esta ayuda, va ligada a un acto de rebeldía, en el cual el Muntu refleja su insatisfac- ción ante las acciones de la Loba Blanca. Esto es claro, cuando uno de los esclavizados kru, a bordo de una de las naos negreras, quien "Sobre su hombro tiene tatuadas dos serpientes y juro que se mueven debajo de la piel" (Zapata, 1983 , p. 86), logra inquietar a otros y así pueden apoderarse del barco a través de una rebelión. Mientras esto ocurre Sosa Illamba da a luz a otro elegido de Elegba, un niño que "En mitad de su pecho, mordiéndose los rabos, pudimos ver que se movían las dos serpientes de Elegba" (p. 90), encargado de guiar al Muntu en la nueva tierra.

En la nueva tierra, América, el elegido es el hijo de Potenciana Biojó. Benkos Biojó, nace marcado con el signo de Elegba en el hombro y será el encargado de guiar a los esclavizados al reino de los mayores, como lo hizo su padre, un esclavizado que: "Se destaca entre los esclavos por la cantidad de sus cadenas: argolla al cuello, grillos en los pies y una barra de hierro que sujetaba sus muñecas (...) Pueden ver que tu padre tenía sobre las espaldas las dos serpientes de Elegba" (Zapata, 1983, pp. 120-121). Y por ello rápidamente es fusilado, sin embargo el abuelo Ngafúa revela "que ya creces en el vientre de tu madre por mandato de Changó" (p. 123).

$\mathrm{Y}$ al nacer, una de las tantas señales que develan a su madre el papel que cumplirá ante su pueblo, le es dado a través de dos serpientes que se devoran las colas. Estas serpientes "Son las sombras de tu amo Simón y del Almirante José Prudencio. Combatirán juntos por la Independencia de sus países pero no se ponen de acuerdo para darnos la libertad" (Zapata, 1983, p. 236).

Ellos no serían los únicos marcados con el signo de Elegba, visitados por un ancestro e impulsados a luchar por la libertad de su pueblo, también lo sería Agne Brown, una joven escogida por Changó para liderar en Norte América esta ardua tarea, con miras a que "El Muntu surge valiente, fortalecido de todas sus heridas (Zapata, 1983, p. 342). La marca del signo de Elegba no es superficial, como la marca de la carimba que la Loba Blanca puso en la piel de los esclavizados. Esta marca se inflama cuando revive su propia historia, cuando refleja su propia memoria, es ahí cuando el Muntu comprende que no es solo una simple rebelión, sino, que el verdadero significado es estar:

En guerra a muerte contra el régimen esclavista que no conocía piedad ni ofrece cuartel al oprimido. Sufrir dieciocho y veinte horas de trabajo forzado es participar en una batalla donde los sobrevivientes son simples cadáveres desposeídos de alma, músculos y vida (...). Así las cosas (...) una ba- 
talla más en la gran guerra contra la esclavitud (Zapata, 1983, p. 392).

Solo entonces el Muntu desata su cólera, ejemplo de ello es la revuelta organizada en Virginia por George Boxley. Protegido de Changó y marcado con el signo de Elegba en la frente, predica el sermón de la libertad y logra organizar: "una revuelta (...) y aunque él logra escapar, seis de los ekobios fueron colgados y otros tantos serán vendidos y desterrados por la delación de una esclava" (Zapata, 1983, p. 399).
En conclusión, la resistencia manifiesta un lenguaje libertario, nacido de las entrañas de los rebeldes, quienes no tienen miedo de señalar al enemigo de la esclavitud, al ser que se deja arrastrar por la ambición y la explotación del hombre por el hombre, a través del retumbar del tambor que invita a luchar por la libertad en distintos escenarios, a despertar la conciencia libertaria, es por esto que Zapata Olivella, en Changó, el gran putas, trasciende la visión que por años ha caracterizado a la comunidad afrocolombiana e incluso afroamericana, desde el interior mismo de su alma, erigiendo un nuevo devenir histórico para este pueblo, por medio de una nueva lectura de América que parte de la visión del subalterno, capaz de romper con las líneas geográficas e históricas que le lleven a escribir una nueva historia del Muntu, la cual compile variadas formas de resistencia para defender las creencias de los esclavizados en plena época de colonización europea, lo cual conlleva a una deconstrucción de la imagen del subalterno.

\section{Referencias}

Depreste, R. (1996). Buenos días y adiós a la negritud. En: López (ed.), Literatura francófona II. México: FCE.

Dos Santos, Juana Elbein, Deoscordenes, Dos Santos. (1977). Religión y cultura negra. En: África en América Latina. México: UNESCO, siglo XXI.

Franz, F. (2001). Los condenados de la tierra, $3^{\mathrm{a}}$ ed. México: FCE.

Le Bretón, D. (1995). Antropología del cuerpo y modernidad. Buenos Aires: Nueva Visión.

Ortiz, F. (1978). Contrapunteo cubano del tabaco y el azúcar. Caracas: Biblioteca Ayacucho.

Said, E. (1996). Cultura e Imperialismo. Barcelona: Anagrama.

Said, E. (2002). Orientalismo. Barcelona: Debate.

Zapata, M. (1983). Chango el gran putas. Bogotá: La Oveja Negra. 